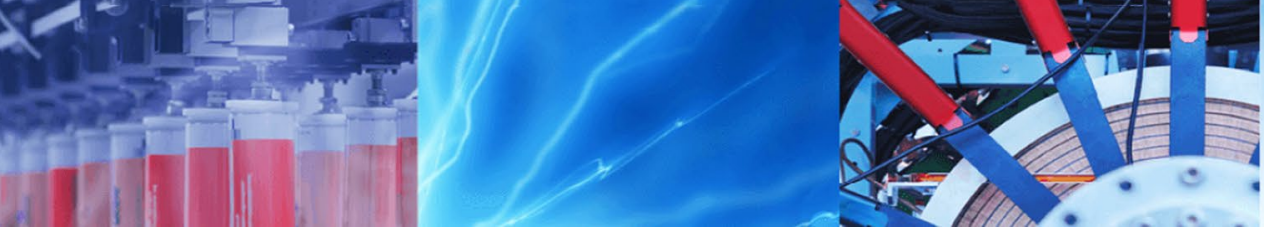

Research Article

\title{
Mode coupling internal resonance characteristics of submerged floating tunnel tether
}

\author{
Sheng-nan Sun ${ }^{1}$ D $\cdot$ Yu-long Pan ${ }^{1} \cdot$ Zhi-bin Su$^{1}$ \\ Received: 19 August 2021 / Accepted: 27 October 2021 \\ Published online: 10 November 2021 \\ (c) The Author(s) 2021 OPEN
}

\begin{abstract}
This study presents the mode coupling internal resonance characteristics of submerged floating tunnel tether. In which, in-plane and out-of-plane coupling of tether is taken into account. And the coupled vibration equations of tether for the in-plane first mode and out-of-plane first mode are obtained. The one-to-one mode coupling internal resonance characteristics of submerged floating tunnel tether are studied by numerical analysis method. It is shown that, when the conditions of modal coupling internal resonance are met, with the increase of the external excitation amplitude of the tether, the mid-span displacement of the tether increases gradually. When the amplitude of external excitation is less than a certain value, the internal resonance of tether will not occur. With the increase of damping ratio, the midspan displacement of the tether decreases gradually. When the damping ratio increases to a certain value, the internal resonance will not occur. The study is helpful to restrain the vibration of submerged floating tunnel tether.
\end{abstract}

\section{Article Highlights}

- When the tether is only subjected to in-plane or out of plane harmonic loads, if the first-order in-plane and out of plane frequencies of tether are close to each other, the tether is prone to occur modal coupling internal resonance.

- Since the frequencies of in-plane and out-of-plane of the tether are not exactly the same. Thus, when modal coupling internal resonance occurs, the external excitation frequency is closer to the first-order modal frequency of the nonload acting plane.

- When excitation amplitude is a fixed value, increasing the damping ratio may inhibit the occurrence of mode coupling internal resonance and effectively reduce the mid-span amplitude of tether.

Keywords Submerged floating tunnel $\cdot$ Tether $\cdot$ Harmonic load $\cdot$ Internal resonance $\cdot$ Sag

\section{Introduction}

Compared with bridge, immersed tunnel and subsea tunnel, submerged floating tunnel (SFT) is probably the most concerned way to cross water area, which is suspended in the appropriate position of water by the balance of buoyancy and anchoring force. Depending on its unique structural form and potential application prospect, submerged floating tunnel has become a competitive scheme in crossing water region, environmental protection and reducing project cost among various structures [1, 2]. Submerged floating tunnel may be anchored by tension

Sheng-nan Sun, sunshengnan1982@163.com | 'School of Architecture and Civil Engineering, Liaocheng University, Liaocheng 252059, Shandong, China.

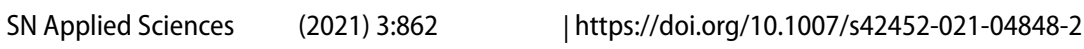


legs, tethers, pontoons and fix supports. Among them, submerged floating tunnel anchored by tethers is suitable for the environmental conditions of medium water depth and is selected as research object here.

Since the concept of submerged floating tunnel was put forward, a large number of studies emerged. Most of these studies focus on the related fields of submerged floating tunnel tether $[3,4]$, and there are also some studies on the overall dynamic response of submerged floating tunnel structure $[5,6]$. Since the operation of submerged floating tunnel is affected by many factors, such as current (including undercurrent), wave, earthquake, vehicle load, etc., so there are studies involving current (including undercurrent) [7], wave $[8,9]$, earthquake $[10,11]$ and vehicle load [12].

Submerged floating tunnel tethers are light, very flexible and lightly damped, which make them particularly prone to vibration. Therefore, the tether of the submerged floating tunnel is similar to the cable of cable-stayed bridge. Difference is that the tether of submerged floating tunnel is in the water. When the tether oscillates, the acting force induced by water should be considered.

Through the observation of cable-stayed bridges being built or having been built, it is indicated that some cables of cable-stayed bridges sometimes vibrate greatly under the environmental load, which is harmful to the safety and durability of bridges [13]. It may cause fatigue fracture of cable, produce fatigue crack at the joint of cable, destroy the anti-corrosion system of cable, and even cause cable failure in serious cases. There are many mechanisms of cable-stayed bridge vibration, one of the most important is mode coupling internal resonance. Experts at home and abroad have done a lot of research on the mode coupling internal resonance of cables. Lacarbonara et al. [14] analyzed the 1:1 internal resonance characteristics of stay cables in one-dimensional continuous system. Benedettini et al. [15] analyzed a four-degree-of-freedom model of a cable under the multiple internal resonance which is a coexistence of 1:1 internal resonance and 1:2 internal resonance. Zhang and Tang [16] investigated the global bifurcation and chaotic dynamics of a cable. Zhao et al. [17] investigated the two-mode nonlinear response of a suspended cable subjected to super-harmonic resonance with 1:3 internal resonance, and discussed the effects of parameters on the steady solution. Casciati et al. [18] studied the nonlinear dynamics of cable with semi-active tuned mass damper. Zhao et al. [19] investigated a twodegree-of-freedom bifurcation system for an elastic cable with 1:1 internal resonance. Zhao et al. [20] simplified the cable-stayed bridge as a single degree of freedom vibrator-cable model and analyzed the internal resonance dynamic response of the cable-stayed bridge under vertical excitation. Wei et al. [21] considering cable sag and the nonlinear influence caused by mode coupling between the beam and the cable, obtained the mode time history curves of the beam and the cable under different internal and external resonance.

In this paper, the partial differential equation of the inplane and out-of-plane coupling nonlinear vibration system of submerged floating tunnel tether is established. Subsequently, the coupling vibration equation reflecting the first-order mode in the plane and out of the plane is obtained by Galerkin method. The 1:1 mode coupling characteristic of the submerged floating tunnel tether is analyzed by numerical analysis, which is helpful to restrain the vibration of anchor cable.

\section{Establishment of vibration equation of tether}

The design sketch of submerged floating tunnel supported by tethers is shown in Fig. 1. The coordinate system as shown in Fig. 2 is established. The plane where the two ends of static tether are connected is defined as $x-y$ plane. The vibration in the $x-y$ plane is defined as in-plane vibration, and the vibration in the $x-z$ plane is defined as out-of-plane vibration. Assumptions: (1) the initial tension of tether is much larger than its own gravity, and the change of tension along the length is ignored. (2) The bending stiffness, torsional stiffness and shear stiffness of the tether are ignored, and the axial deformation of tether is small enough to be ignored. (3) Only geometric nonlinearity of tether is considered, and the tether material is linear elastic material (the deformation constitutive relation satisfies Hooke's law). According to Newton's law, the in-plane and out-of-plane vibration equations of tether are established. The distance of the two ends of static tether is $L . T$ is the initial tangential tension.

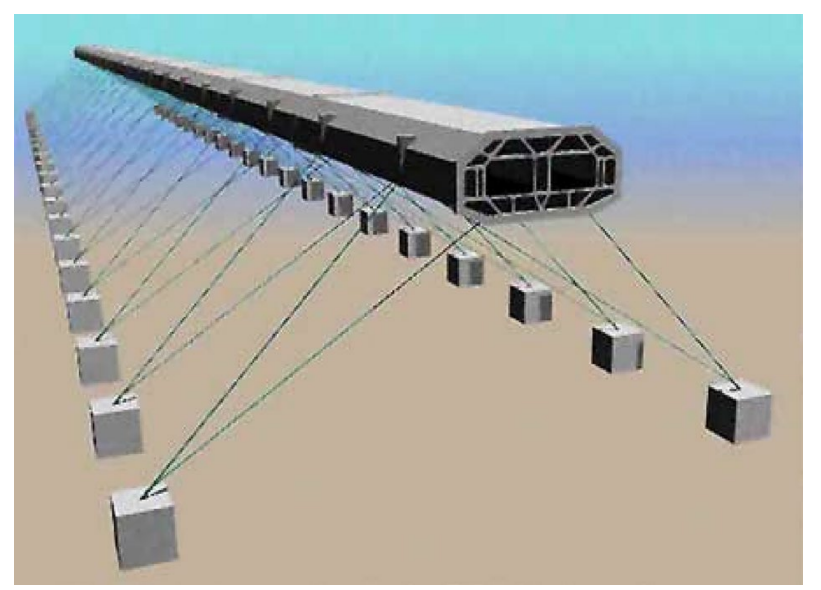

Fig. 1 Submerged floating tunnel supported by tethers 


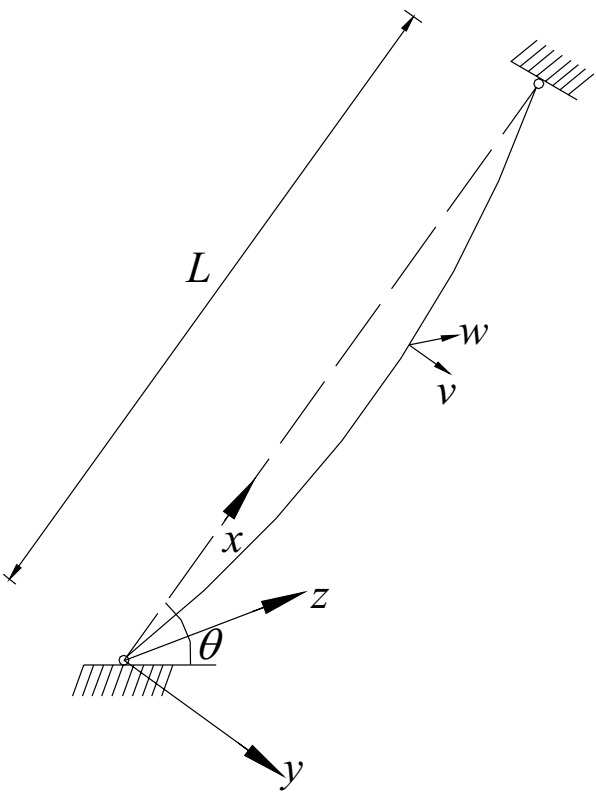

Fig. 2 Vibration model of tether

$\frac{\partial}{\partial s}\left[(T+\tau) \cdot\left(\frac{d y}{d s}+\frac{\partial v}{\partial s}\right)\right]+f_{y}(t)=m \frac{\partial^{2} v}{\partial t^{2}}+c_{1} \frac{\partial v}{\partial t}+F_{D v}-v_{s} \gamma_{f} \cos \theta$

$\frac{\partial}{\partial s}\left[(T+\tau) \cdot \frac{\partial w}{\partial s}\right]+f_{z}(t)=m \frac{\partial^{2} w}{\partial t^{2}}+c_{2} \frac{\partial w}{\partial t}+F_{D w}$

In the formula, $v$ and $w$ are displacement measured from the static equilibrium in $y$ and $z$ directions respectively. $m$ is the quality of tension leg unit length. $\tau$ is the additional tangential dynamic tension generated by the vibrating of the tether. $s$ is Lagrange coordinate. $c_{1}$ and $c_{2}$ are internal damping coefficients of tether respectively. $f_{y}(t)$ and $f_{z}(t)$ are in-plane and out-plane harmonic excitation on unit length tether respectively. $\gamma_{f}$ is buoyant unit weight of the tether. $V_{s}$ is the volume per unit length of the tether. $y$ is the sag curve of the static tether.

According to the Morison equation, when the tether oscillates, the total acting force induced by water per unit length may be expressed as the sum of the damping force and the additional inertial force [1].

$F_{D V}=\frac{1}{2} \rho_{\mathrm{w}} D C_{\mathrm{D}} \dot{v}|\dot{v}|+C_{\mathrm{m}} \frac{\pi D^{2}}{4} \rho_{\mathrm{w}} \ddot{v}$

$F_{D w}=\frac{1}{2} \rho_{\mathrm{w}} D C_{\mathrm{D}} \dot{W}|\dot{W}|+C_{\mathrm{m}} \frac{\pi D^{2}}{4} \rho_{\mathrm{w}} \ddot{W}$

In which, $\rho_{w}$ is the density of water, $D$ is the diameter of the tether, $C_{m}$ is the additional mass coefficient, $C_{D}$ is the drag coefficient. Suppose $C_{m}=1, C_{D}=0.7$ [22].
The arc length before deformation (static) and after deformation are defined as $d s$ and $d s^{\prime}$ respectively. If the influence of axial deformation is not considered, the following equations are obtained.

$d^{2} s=d^{2} x+d^{2} y$

$d^{2} s^{\prime}=d^{2} x+(d y+d v)^{2}+d^{2} w$

$\varepsilon=\frac{d s^{\prime}-d s}{d s} \approx \frac{d y}{d s} \cdot \frac{d v}{d s}+\frac{1}{2}\left[\left(\frac{\partial w}{\partial s}\right)^{2}+\left(\frac{\partial v}{\partial s}\right)^{2}\right]$

In which, $\varepsilon$ is the dynamic strain.

It is assumed that the ratio of static displacement in the middle of the tether $f$ to the unstretched length of tether $L$ ranges from nearly zero to about $1 / 8$. With the assumption, the static equilibrium position of the tether can be approximated by the quadratic parabola.

$y=4 f \frac{X}{L}\left(1-\frac{X}{L}\right)$

In the equation, $f=V_{s} \gamma_{f} \cos (\theta) L^{2} /(8 H)$ and the following relation is given.

$\frac{\tau}{h}=\frac{T}{H}=\frac{d s}{d x}$

In which, $H$ and $h$ are static tension and dynamic tension along the chord respectively.

Based on Eqs. (7) and (9), the following equation is obtained.

$h\left(\frac{\mathrm{d} s}{\mathrm{~d} x}\right)^{3}=E A\left\{y_{x} v_{x}+\frac{1}{2}\left[\left(\frac{\partial v}{\partial x}\right)^{2}+\left(\frac{\partial w}{\partial x}\right)^{2}\right]\right\}$

$E$ and $A$ denote the modulus of elasticity and the sectional area respectively. Equation (11) is obtained by integrating Eq. (10).

$h=\frac{E A}{L_{E}}\left\{\int_{0}^{L} y_{x} v_{x} \mathrm{~d} x+\frac{1}{2} \int_{0}^{L}\left[\left(\frac{\partial v}{\partial x}\right)^{2}+\left(\frac{\partial w}{\partial x}\right)^{2}\right] \mathrm{d} x\right\}$

$L_{\mathrm{E}}=L\left[1+8(f / L)^{2}\right]$

Considering the excitation in $y$ and $z$ direction, based on Eqs. (1) and (2), Eqs. (13) and (14) are obtained.

$m \frac{\partial^{2} v}{\partial t^{2}}+c_{1} \frac{\partial v}{\partial t}-h \frac{\partial^{2} v}{\partial z^{2}}-h\left[\frac{\partial}{\partial x} \cdot\left(y_{x}+v_{x}\right)\right]=-F_{D v}+f_{y}(t)$

$m \frac{\partial^{2} w}{\partial t^{2}}+c_{1} \frac{\partial w}{\partial t}-H \frac{\partial^{2} w}{\partial z^{2}}-h\left[\frac{\partial}{\partial x} \cdot\left(w_{x}\right)\right]=-F_{D w}+f_{z}(t)$ 
Assuming that modal solutions of the first-order inplane mode and out of plane mode are written as Eqs. (15) and (16).

$v=V(t) \cdot \phi(x)$

$w=W(t) \cdot \varphi(x)$

In which, $V$ and $W$ are generalized coordinates of inplane and out of plane modes. $\phi(x)$ and $\varphi(x)$ are corresponding modal functions. The linear vibration mode of tether is selected as follows [23].

$\phi(x)=\frac{1-\tan (\omega / 2) \cdot \sin (\omega \cdot x / L)-\cos (\omega \cdot x / L)}{1-\tan (\omega / 2) \cdot \sin (\omega / 2)-\cos (\omega / 2)}$

$\varphi(x)=\sin \left(\frac{\pi \cdot x}{L}\right)$

$\omega$ is determined by the following transcendental equation.

$\tan \left(\frac{\omega}{2}\right)=\frac{\omega}{2}-\frac{4}{\lambda^{2}}\left(\frac{\omega}{2}\right)^{3}$

$\lambda^{2}=\frac{\left(\gamma_{f} V_{s} \cos \theta\right)^{2} L^{3} E A}{\left(H_{0}^{3} L_{E}\right)}$

By Galerkin method, Eqs. (13) and (14) are simplified as follows.

$\ddot{V}+2 \xi_{1} \omega_{1} \dot{V}+\omega_{1}^{2} V+\gamma_{1} V^{2}+\gamma_{2} W^{2}+\gamma_{3} V^{3}+\gamma_{4} V W^{2}+\frac{2 D_{V}}{L \cdot \bar{m}}=F_{y}(t)$

$\ddot{W}+2 \xi_{2} \omega_{2} \dot{W}+\omega_{2}^{2} W+\gamma_{5} W V+\gamma_{6} W V^{2}+\gamma_{7} W^{3}+\frac{2 D_{W}}{L \cdot \bar{m}}=F_{z}(t)$

$D_{\mathrm{V}}=\frac{1}{2} \rho_{\mathrm{w}} D C_{\mathrm{D}} \int_{0}^{L}[\dot{V} \phi(x)]^{2} \operatorname{sgn}[\dot{V} \phi(x)] \sin \left(\frac{\pi x}{L}\right) \mathrm{d} x$

$D_{\mathrm{W}}=\frac{1}{2} \rho_{\mathrm{w}} D C_{\mathrm{D}} \int_{0}^{L}[\dot{W} \varphi(x)]^{2} \operatorname{sgn}[\dot{W} \varphi(x)] \sin \left(\frac{\pi x}{L}\right) \mathrm{d} x$

In which, $\bar{m}$ is the sum of the tether mass and addedmass per unit unstretched length. $F_{y}(t)$ and $F_{z}(t)$ are inplane and out of plane harmonic loads respectively, and $F_{y}(t)=Q \cos \omega_{\mathrm{v}} t, F_{z}(t)=R \cos \omega_{w} t . Q$ and $R$ are in-plane and out of plane excitation amplitudes respectively. $\omega_{v}$, $\omega_{w}$ are in-plane and out of plane excitation frequencies respectively.

\section{Numerical analysis and results}

Basic parameters of tether are shown in Table 1 [24]. In the numerical analysis, the following values are chosen unless noted otherwise- $0.0001 \mathrm{~m}$ for initial displacement disturbance of in-plane and out-of-plane, 0 for initial velocity, $2.2 \mathrm{kN} / \mathrm{m}$ for in-plane excitation amplitude and $3 \mathrm{kN} / \mathrm{m}$ for out of plane excitation amplitude.

From Table 1, it can be seen that the first mode natural frequencies of tether of in-plane and out of plane are close to each other. That is to say, the tether is possible to occur 1: 1 mode coupling internal resonance. Therefore, the 1:1 mode coupling internal resonance of tether is analyzed, in which only in-plane or out of plane load is considered. When the in-plane frequency ratio $\left(\omega_{v} / \omega_{1}\right.$, the ratio of the in-plane excitation frequency to the first-order natural inplane frequency of tether) is 1 and the in-plane excitation amplitude $Q$ is $2.2 \mathrm{kN} / \mathrm{m}$, the in-plane and out of plane mid-span displacement time history curves of tether are shown in Fig. 3. It can be seen from Fig. 3 that the in-plane vibration of tether is rapidly excited at the initial moment. The maximum amplitude vibration is basically maintained within the first $100 \mathrm{~s}$. Here the tether is not affected by the out of plane load. Due to the mode coupling effect, the out-of-plane vibration of tether is excited after $50 \mathrm{~s}$. At the same time, the in-plane amplitude of tether is reduced, and the energy is transferred from in-plane to out of plane.

When the out-of plane frequency ratio $\left(\omega_{w} / \omega_{2}\right.$, the ratio of the out-of-plane excitation frequency to the first-order natural out-of-plane frequency of tether) is 1.15 and the out-of-plane excitation amplitude $R$ is $3 \mathrm{kN} / \mathrm{m}$, the in-plane and out of plane mid-span displacement time history curves of tether are shown in Fig. 4. It can be seen from Fig. 4 that the out of plane vibration of tether is rapidly excited at the initial moment. The maximum amplitude

Table 1 Basic parameters of tether

\begin{tabular}{ll}
\hline Parameters & Value \\
\hline Length/m & 161.66 \\
Cross-sectional area/( $\left.\mathrm{m}^{2}\right)$ & 0.1878 \\
Mass per unit length $(\mathrm{kg} / \mathrm{m})$ & 1474.23 \\
Initial velocity/(m/s) & 0 \\
Density $\left(\mathrm{kg} / \mathrm{m}^{3}\right.$ ) & 7850 \\
Elastic modulus/Pa & $2.1 \times 10^{11}$ \\
Initial tension force/N & $2.572 \times 10^{7}$ \\
Damping ratio & 0.0018 \\
In-plane first-order natural circular frequency/(rad/s) & 2.66 \\
Out-of-plane first-order natural circular frequencies/ & 2.41 \\
$\quad$ (rad/s) & \\
Inclination & $60^{\circ}$ \\
\hline
\end{tabular}




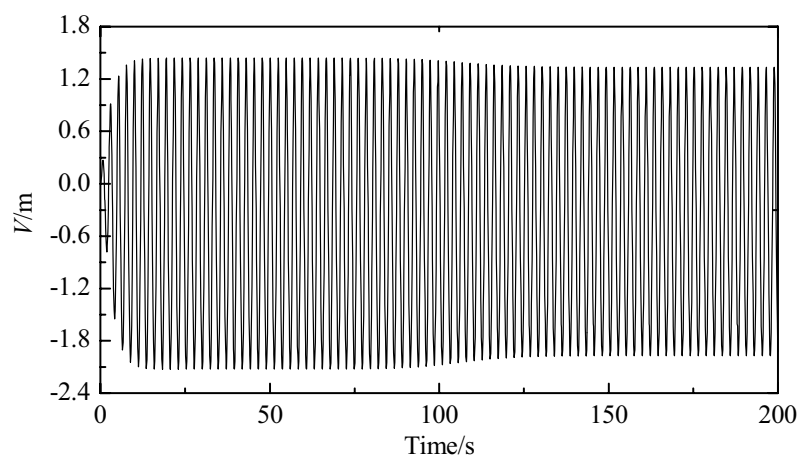

(a) in-plane

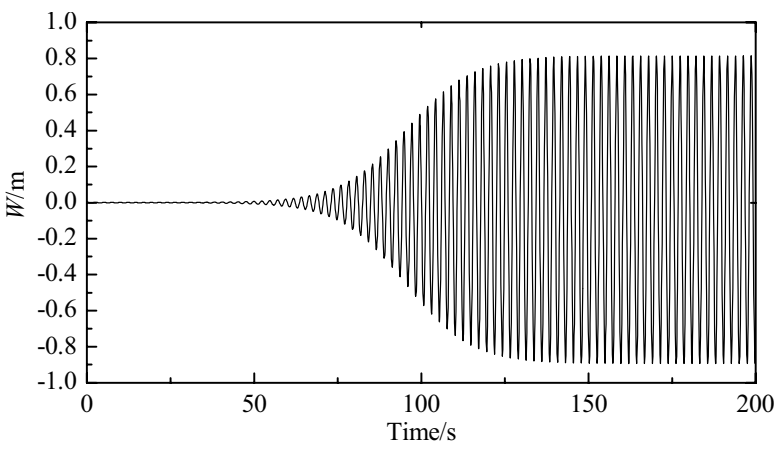

(b) out of plane

Fig. 3 Mid-span displacement history cures of tether while $\omega_{v} / \omega_{1}=1$ and $Q=2.2 \mathrm{kN} / \mathrm{m}$

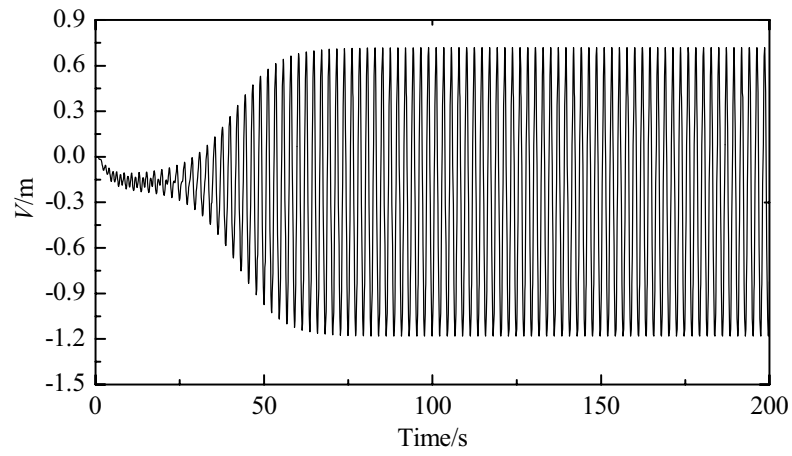

(a) in-plane

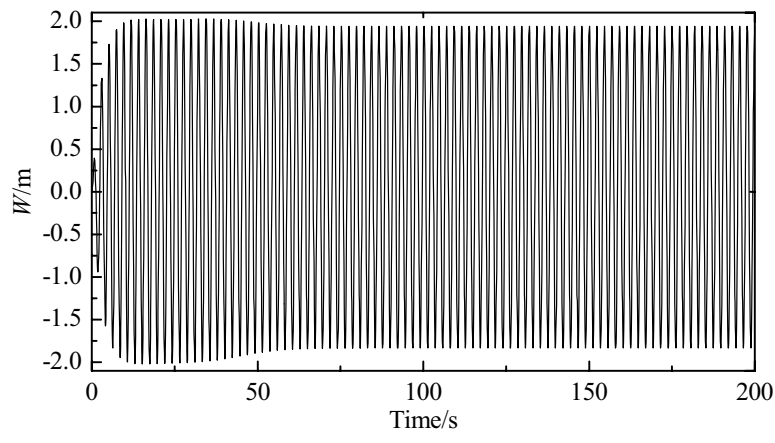

(b) out of plane

Fig. 4 Mid-span displacement history cures of tether while $\omega_{w} / \omega_{2}=1.15$ and $R=3 \mathrm{kN} / \mathrm{m}$

vibration is basically maintained within the first $50 \mathrm{~s}$. Here the tether is not affected by the in-plane load. Due to the mode coupling effect, the in-plane vibration of tether is excited after $25 \mathrm{~s}$. At the same time, the out-of-plane amplitude of tether is reduced, and the energy is transferred from out of plane to in-plane. It can be seen that when the tether is only subjected to in-plane or out of plane harmonic loads, if the first-order in-plane and out of plane frequencies of tether are close to each other, the tether is prone to occur modal coupling internal resonance.

\subsection{Influence of excitation frequency on mode coupling internal resonance of tether}

While only in-plane load is considered, the influence of in-plane frequency ratio on the mode coupling vibration characteristics of tether is shown in Fig. 5 . It is shown that, when the in-plane frequency ratio is within $0.9-1.02$, the out-of-plane vibration of the tether is excited. When the in-plane frequency ratio is outside of that range, only in-plane vibration of tether occurs. That is to say, when

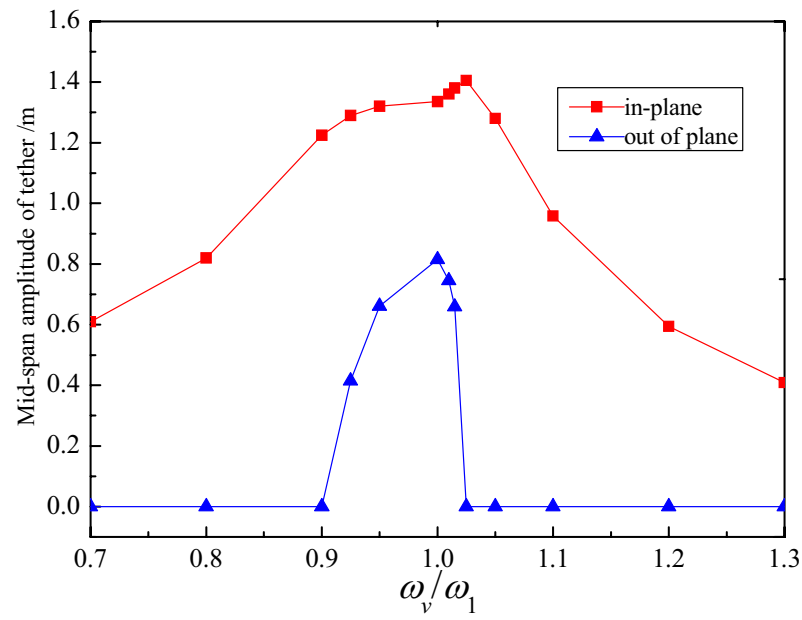

Fig.5 Relationship between maximum mid-span displacement of tether and in-plane frequency ratio

the excitation amplitude $Q$ is $2.2 \mathrm{kN} / \mathrm{m}$ and the in-plane frequency ratio is within $0.9-1.02$, the $1: 1$ mode coupling internal resonance of tether occurs. Here the excitation 
frequency corresponding to the initial value of in-plane frequency ratio interval is $2.394 \mathrm{rad} / \mathrm{s}$, which is closer to the first out-of-plane natural frequency.

While only out-of-plane load is considered, the influence of out-of-plane frequency ratio on the mode coupling vibration characteristics of tether is shown in Fig. 6. It is shown that, when the out-of-plane frequency ratio is within 1.1-1.22, the in-plane vibration of the tether is excited. When the out-of-plane frequency ratio is outside of that range, only out-of-plane vibration of tether occurs. That is to say, when the excitation amplitude $R$ is $3 \mathrm{kN} / \mathrm{m}$ and the out-of-plane frequency ratio is within 1.1-1.22, the 1:1 mode coupling internal resonance of tether occurs. Here the excitation frequency corresponding to the initial value of out-of-plane frequency ratio interval is $2.65 \mathrm{rad} / \mathrm{s}$, which is closer to the first in-plane natural frequency.

To sum up, since in-plane frequency of the tether is not exactly the same as the out-of-plane frequency, when modal coupling internal resonance occurs, the external excitation frequency is closer to the first-order modal frequency of the non-load acting plane.

\subsection{Influence of excitation amplitude on mode coupling internal resonance of tether}

In order to analyze the influence of excitation amplitude on mode coupling internal resonance of tether, it is assumed that only in-plane load is considered and $\omega_{\mathrm{v}} / \omega_{1}=1$. When excitation amplitude $Q$ changes from 0 to $3 \mathrm{kN} / \mathrm{m}$, relationship between mid-span amplitude of tether and excitation amplitude is shown in Fig. 7. It can be seen from Fig. 7 that maximum in-plane and out-of-plane displacement increases as excitation amplitude increases. Maximum in-plane displacement is always larger than that

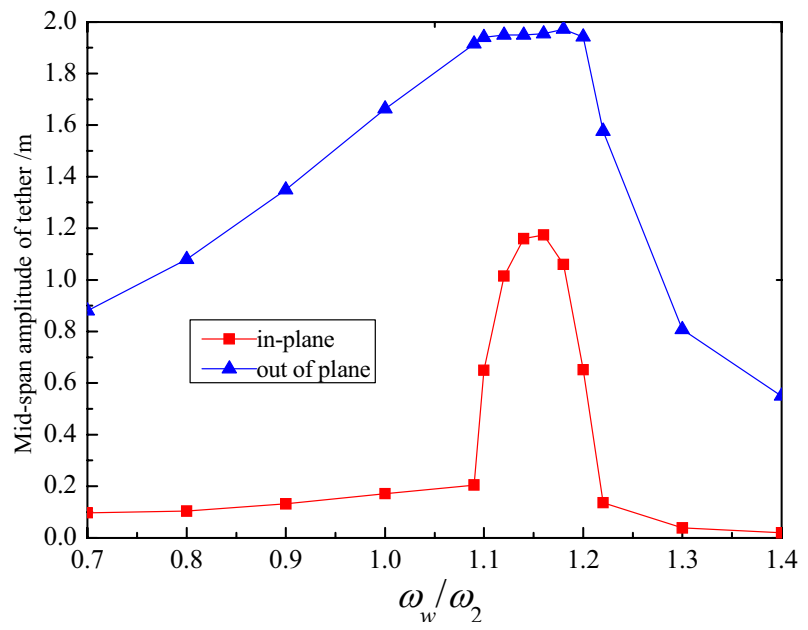

Fig.6 Relationship between maximum mid-span displacement of tether and out-of-plane frequency ratio of out of plane, since only in-plane load is considered. When the in-plane excitation amplitude is less than 1.75 $\mathrm{kN} / \mathrm{m}$, mode coupling internal resonance cannot occur.

If it is assumed that only out-of-plane load is considered and $\omega_{w} / \omega_{2}=1.15$, when excitation amplitude $R$ changes from 0 to $3 \mathrm{kN} / \mathrm{m}$, relationship between mid-span amplitude of tether and excitation amplitude is shown in Fig. 8. It can be seen from Fig. 8 that maximum in-plane and outof-plane displacement increases as excitation amplitude increases. Maximum out-of-plane displacement is always larger than that of in-plane, since only out-of-plane load is considered. When the out-of-plane excitation amplitude is less than $1.75 \mathrm{kN} / \mathrm{m}$, mode coupling internal resonance cannot occur.

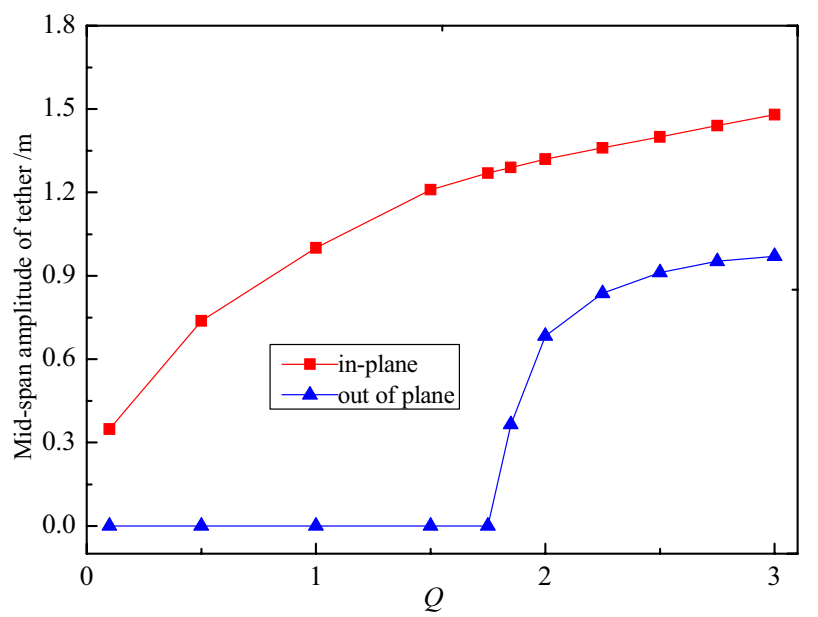

Fig. 7 Relationship between mid-span amplitude of tether and excitation amplitude when only in-plane load is considered

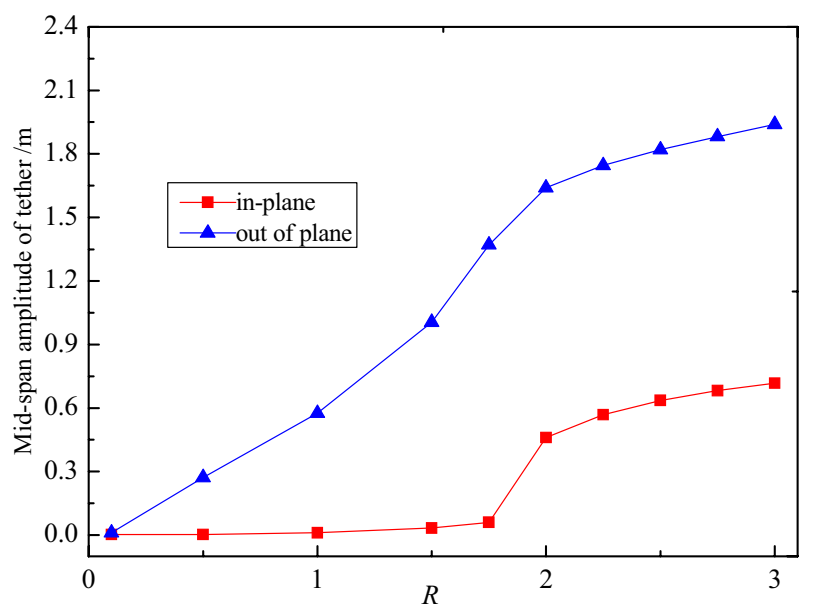

Fig. 8 Relationship between mid-span amplitude of tether and excitation amplitude when only in-plane load is considered 


\subsection{Influence of damping ratio on mode coupling internal resonance of tether}

In order to analyze the influence of damping ratio on mode coupling internal resonance of tether, it is assumed that only in-plane load is considered and $\omega_{\mathrm{v}} / \omega_{1}=1$. When excitation amplitude $Q$ is $2.2 \mathrm{kN} / \mathrm{m}$ and initial disturbance is $0.0001 \mathrm{~m}$, relationship between mid-span amplitude of tether and damping ratio is shown in Fig. 9. It can be seen from Fig. 9 that with the increase of the damping ratio in and out of tether plane, maximum in-plane midspan displacement of tether decreases gradually, while maximum out-of-plane mid-span displacement of tether is not affected by damping ratio at all. When the damping ratio is less than 0.015 , maximum out-of-plane mid-span displacement of tether decreases rapidly with the increase of the damping ratio. When damping ratio reaches to the certain range of $0.015-0.025$, mode coupling internal resonance does not occur. Only in-plane movement appears. It is concluded that when excitation amplitude is a fixed value, increasing the damping ratio may inhibit the occurrence of mode coupling internal resonance and effectively reduce the mid-span amplitude of tether.

\section{Discussion}

According to the research results of cables for cable-stayed bridges, when the first order natural in-plane and out-ofplane frequencies are close or equal to each other, internal resonance phenomenon may occur in cables. Its essence is that the in-plane (out-of-plane) motion of the cable has an exciting effect on that of out-of-plane (in-plane) motion. This kind of coupling may produce a large nonlinear

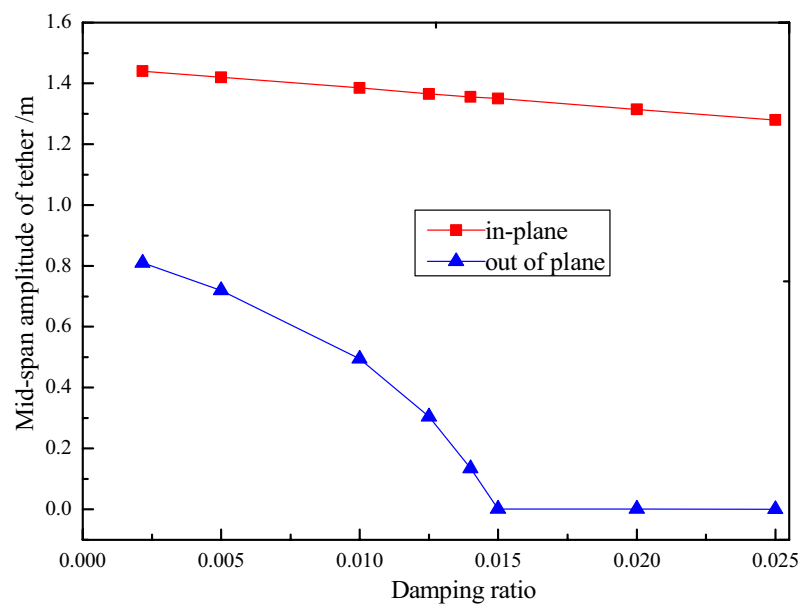

Fig. 9 Relationship between maximum mid-span displacement and damping ratio of tether response, which is usually called internal resonance [25]. Submerged floating tunnel tether is similar to the cable of cable-stayed bridge. The dynamic characteristics of tether are between those of standard string and cable with large sag, which are more inclined to the nonlinear characteristics of the standard string. However, submerged floating tunnel tether is in water. Its vibration is affected by damping force and additional inertial force which are induced by water. Thus, according to the characteristics of the submerged floating tunnel tether, whether the tether produces 1:1 mode coupling internal resonance is studied. It is obtained that the tether will produce 1:1 mode coupling internal resonance when certain conditions are met. This phenomenon is similar to the findings of Lacarbonara [14] and Zhao [19].

Since in-plane frequency of the tether is not exactly the same as the out-of-plane frequency, when modal coupling internal resonance occurs, the external excitation frequency is closer to the first-order modal frequency of the non-load acting plane. This phenomenon is similar to the findings of Mei [26].

\section{Conclusions}

In this paper, the partial differential equation of the inplane and out-of-plane coupling nonlinear vibration system of submerged floating tunnel tether is established. According to linear vibration modes of tether, the partial differential equation was converted into ordinary differential equations by Galerkin method and the coupled vibration equation of tether for the in-plane first mode and outof-plane first mode was obtained. The one-to-one mode coupling internal resonance characteristics of submerged floating tunnel tether was studied by numerical analysis method.

1. Since the in-plane frequency of tether is not exactly the same as the out-of-plane frequency, when modal coupling internal resonance occurs, the external excitation frequency is closer to the first-order modal frequency of the non-load acting plane.

2. When the tether is only subjected to in-plane or out of plane harmonic loads, if the first-order in-plane and out of plane frequencies of the tether meet the resonance conditions, the tether is prone to occur modal coupling internal resonance.

3. When the conditions of modal coupling internal resonance are met, with the increase of the external excitation amplitude of the tether, the mid-span displacement of the tether increases gradually. With the increase of damping ratio, the mid-span displacement of the tether decreases gradually. 
4. When the amplitude of external excitation is less than a certain value, the internal resonance of tether will not occur. When the damping ratio increases to a certain value, the internal resonance will not occur.

Acknowledgements This work was financially supported by the Liaocheng University Students' innovation and entrepreneurship training program (Grant No. CXCY2021040) and the College Students' innovation and entrepreneurship training program of Shandong province (Grant No. S202110447028) and the Research Fund of Liaocheng University (Grant No. 318011916).

Availability of data and material The data used to support the findings of this study are available from the corresponding author upon request.

\section{Declarations}

Conflict of interest The authors declare that there are no conflicts of interest regarding the publication of this paper.

\section{Appendix}

$\gamma_{1}=-\gamma \frac{l_{2} I_{3}+0.5 I_{4} I_{5}}{\bar{m} l_{1}}, \gamma_{2}=-0.5 \gamma \frac{l_{4} I_{6}}{\bar{m} l_{1}}, \gamma_{3}=-0.5 \gamma \frac{l_{2} I_{5}}{\bar{m} l_{1}}$,

$\gamma_{4}=-0.5 \gamma \frac{I_{2} I_{6}}{\bar{m} l_{1}}, \gamma_{5}=-\gamma \frac{I_{3} I_{8}}{\bar{m} I_{7}}, \gamma_{6}=-0.5 \gamma \frac{I_{5} I_{8}}{\bar{m} l_{7}}, \gamma_{7}=-0.5 \gamma \frac{I_{6} I_{8}}{\bar{m} I_{7}}$,

$I_{1}=\int_{0}^{L} \phi^{2} d x, I_{2}=\int_{0}^{L} \phi \phi_{x x} d x, I_{3}=\int_{0}^{L} y_{x} \phi_{x} d x, I_{4}=\int_{0}^{L} y_{x x} \phi d x$,

$I_{5}=\int_{0}^{L} \phi_{x}^{2} d x, I_{6}=\int_{0}^{L} \varphi_{x}^{2} d x, I_{7}=\int_{0}^{L} \varphi^{2} d x, I_{8}=\int_{0}^{L} \varphi \varphi_{x x} d x$,

$\omega_{1}^{2}=-\frac{H I_{2}+\gamma I_{3} I_{4}}{m I_{1}}, \omega_{2}^{2}=-\frac{H I_{8}}{m I_{7}}, \gamma=\frac{E A}{L}, y_{x}=4 f\left(\frac{1}{L}-\frac{2 x}{L^{2}}\right)$

$y_{x x}=-\left(\frac{8 f}{L^{2}}\right), \varphi_{x}=\frac{\pi}{L} \cos \left(\frac{\pi \cdot x}{L}\right), \varphi_{x x}=-\left(\frac{\pi}{L}\right)^{2} \sin \left(\frac{\pi \cdot x}{L}\right)$,

$\phi_{x}=\frac{1-\left(\frac{\omega}{L}\right) \tan \left(\frac{\omega}{2}\right) \cdot \cos \left(\frac{\omega \cdot x}{L}\right)+\left(\frac{\omega}{L}\right) \sin \left(\frac{\omega \cdot x}{L}\right)}{1-\tan \left(\frac{\omega}{2}\right) \cdot \sin \left(\frac{\omega}{2}\right)-\cos \left(\frac{\omega}{2}\right)}$,

$\phi_{x x}=\frac{1+\left(\frac{\omega}{L}\right)^{2} \tan \left(\frac{\omega}{2}\right) \cdot \sin \left(\frac{\omega \cdot x}{L}\right)+\left(\frac{\omega}{L}\right)^{2} \cos \left(\frac{\omega \cdot x}{L}\right)}{1-\tan \left(\frac{\omega}{2}\right) \cdot \sin \left(\frac{\omega}{2}\right)-\cos \left(\frac{\omega}{2}\right)}$.

Open Access This article is licensed under a Creative Commons Attribution 4.0 International License, which permits use, sharing, adaptation, distribution and reproduction in any medium or format, as long as you give appropriate credit to the original author(s) and the source, provide a link to the Creative Commons licence, and indicate if changes were made. The images or other third party material in this article are included in the article's Creative Commons licence, unless indicated otherwise in a credit line to the material. If material is not included in the article's Creative Commons licence and your intended use is not permitted by statutory regulation or exceeds the permitted use, you will need to obtain permission directly from the copyright holder. To view a copy of this licence, visit http://creativecommons. org/licenses/by/4.0\%.

\section{References}

1. Sun SN, Su ZB (2011) Parametric vibration of submerged floating tunnel tether under random excitation. China Ocean Eng 25(2):349-356

2. Østlid H (2001) Submerged floating tunnel (sft), a new type of structure for efficient transport, energysaving, minimizing pollution and environmental impact. In: Proceedings of the 4th symposium on strait crossings, Bergen, Norway, pp 545-546

3. Sheng-nan SUN, Zhi-bin SU, Yun-fen FENG, Xian-yi XU (2020) Parametric vibration analysis of submerged floating tunnel tension legs. China Ocean Eng 34(1):131-136

4. Cantero D, Rønnquist A, Naess A (2016) Recent studies of parametrically excited mooring cables for submerged floating tunnels. Procedia Eng 166:99-106

5. Daniel C, Anders R, Arvid N (2017) Tension during parametric excitation in submerged vertical taut tethers. Appl Ocean Res 65:279-289

6. Man-sheng $D$, Guo-ping $M$, Long-chang $Y$, Zhong-rong $N$, Huan-ping P, Chao-qun $\mathrm{H}$ (2012) Effect of escape device for submerged floating tunnel (SFT) on hydrodynamic loads applied to SFT. J Hydrodyn 24(4):609-616

7. Luo G, Chen JX, Zhou XJ (2015) Effects of various factors on the viv-induced fatigue damage in the cable of submerged floating tunnel. Pol Marit Res 22(4):76-83

8. Jin C, Kim M (2018) Time-domain hydro-elastic analysis of a SFT (submerged floating tunnel) with mooring lines under extreme wave and seismic excitations. Appl Sci 8:2386

9. Muhammad N, Ullah Z, Choi D (2017) Performance evaluation of submerged floating tunnel subjected to hydrodynamic and seismic excitations. Appl Sci 7:1122

10. Lee JH, Seo SI, Mun HS (2016) Seismic behaviors of a floating submerged tunnel with a rectangular cross-section. Ocean Eng 127:32-47

11. Martinelli L, Barbella G, Feriani A (2011) A numerical procedure for simulating the multi-support seismic response of submerged floating tunnels anchored by cables. Eng Struct 33(10):2850-2860

12. Xiang $Y$, Lin $H$, Chen $Z$ (2018) Dynamic response analysis of a submerged floating tunnel subjected to moving load. Chin J Vib Shock 37(4):82-87

13. Gu M, Du XQ (2005) Experimental investigation of rain-windinduced vibration of cables in cable-stayed bridges and its mitigation. J Wind Eng Ind Aerodyn 93(1):79-95

14. Lacarbonara W, Rega G, Nayfeh AH (2003) Resonant non-linear normal modes part I: analytical treatment for structural onedimensional systems. Int J Non-Linear Mech 38(6):851-872

15. Benedettini F, Rega G, Alaggio R (1995) Non-linear oscillation of four-degree-of-freedom model of suspended cable under multiple internal resonance conditions. J Sound Vib 182(5):775-789

16. Zhang W, Tang Y (2002) Global dynamics of the cable under combined parametrical and external excitations. Int J NonLinear Mech 37(3):505-526

\section{SN Applied Sciences}


17. Zhao YY, Li YD, Wang LH, Kang HJ (2007) On one-to-three internal resonances and super harmonic resonances of suspended cables. J Dyn Control 5(2):112-117

18. Casciati F, Ubertini $F$ (2008) Nonlinear vibration of shallow cables with semi active tuned mass damper. Nonlinear Dyn 53(1):89-106

19. Zhao HQ, Chen YS, Li J (2010) Singularity analysis of a twodimensional elastic cable with 1:1 internal resonance. Appl Math Mech 31(2):143-150

20. Zhao Y, Chen WZ, Zheng Y (2015) Dynamic response analysis of internal resonance for cable-stayed bridges under vertical excitation. Chin J Sci Technol Eng 15(11):100-105

21. Wei MH, Xiao YQ (2012) Nonlinear vibration analysis for a cablebeam coupled system under simultaneous internal and external resonances. Chin J Vib Shock 31(7):79-84

22. Zhu YR (1991) Ocean engineering wave mechanics. Tianjin UniversityPress, Tianjin
23. Irvine MH (1981) Cable structure. The MIT Press, Cambridge

24. Faggiano B, Landolfo R, .Mazzolani FM (2001) Design and modelling aspects concerning the submerged floating tunnels: an application to the Messina strait crossing. In: Proceedings of the 4th symposium on strait crossings, Bergen, Norway, pp 511-519

25. Xiao ZR, Sun BN (2008) Internal resonance analysis because of in-plane and out-of-plane coupling effects of the stay cable in the cable-stayed bridge. Chin J Comput Mech 25(2):278-282

26. Mei K, Sun S, Li X, Jin G (2017) Property of mode-coupled internal-resonance of CFRP cables, China. J Highw Transp 30(7):65-72

Publisher's Note Springer Nature remains neutral with regard to jurisdictional claims in published maps and institutional affiliations. 